\title{
A PROFISSIONALIZAÇÃO DO PROFESSOR NO CENÁRIO LEGISLATIVO EXISTENTE
}

\author{
Marcos Gustavo Richter \\ mrichter@cal.ufsm.br \\ Jaci Rene Costa Garcia \\ garciaadv@terra.com.br
}

\section{RESUMO}

Este artigo tem por objetivo debater o problema da profissionalização do professor, examinando alguns aspectos do fundo jurídico do exercício da docência em comparação com o de profissões afins já emancipadas. Partimos de uma pesquisa da legislação existente acerca da educação no Brasil, especificamente no que se refere ao professor enquanto profissão para, num segundo momento, refletirmos sobre as possibilidades e o grau de necessidade da construção de uma regulamentação específica que delimite o universo de atuação desse profissional.

\section{CONSIDERAÇÕES INICIAIS}

O tema envolve uma pesquisa da legislação existente acerca da educação no Brasil, especificamente no que se refere ao professor enquanto profissão para, num segundo momento, refletirmos sobre as possibilidades e o grau de necessidade da construção de uma regulamentação específica que delimite o universo de atuação desse profissional.

Nesse sentido, percorremos o Ordenamento numa análise sistemática e, respeitando a verticalidade das normas, partimos da Constituição Federal, passamos pela Lei de Diretrizes e Bases da Educação e, por fim, são analisadas algumas orientações do Ministério da Educação e do Conselho Nacional de Educação.

As inferências que serão realizadas estão todas sustentadas nos normativos citados e, no curso do trabalho, buscamos também correlações entre a realidade e o cenário legislativo e, a partir desse confronto, surgem perspectivas que podem contribuir para o debate da questão.

Entendemos que é o momento de (re)pensar o papel do professor enquanto profissional, defini-lo enquanto ator de incomparável significado social, delimitar o seu espaço de atuação, regulamentar deveres e direitos no exercício da profissão e, 
efetivamente, criar condições objetivas para a educação no Brasil a partir de um "olhar" para a questão da profissionalização do professor.

Pensando a educação como instância possibilitadora do desenvolvimento pleno da pessoa e do exercício da cidadania (ar. 206, caput), e sabedores do sentido e do alcance da expressão "cidadão" para a qual convergem e se encontram harmonicamente o indivíduo e o Estado, cresce em importância a nossa reflexão sobre a profissionalização dessa atividade que lida com um direito tão fundamental, antecedente necessário ao desenvolvimento humano e a concretização do indivíduo como um cidadão no Estado.

\section{O QUADRO NORMATIVO EXISTENTE: A NORMA CONSTITUCIONAL}

A Carta Política de 1988 quando trata da Educação demonstra que a matéria foi enfocada em toda a sua extensão, apontando que é um direito de todos e um dever do Estado e da família (art. 205, caput), esta como núcleo essencial do Estado e atuando, principalmente, no momento em que o indivíduo inicia suas relações interpessoais e começa a construir a sua personalidade.

Percebemos que a educação pode ser compreendida como um vínculo que une o Estado enquanto ente político e o indivíduo enquanto essência constituinte desse Estado, numa relação que exige profunda seriedade no trato e que o legislador constituinte envolve em princípios (art. 206), os quais destacamos:

"Art 2060 ensino será ministrado com base nos seguintes princípios:

I - igualdade de condições para o acesso e permanência na escola;

II - liberdade de aprender, ensinar, pesquisar e divulgar o pensamento, a arte e o saber;

III - pluralismo de idéias e de concepções pedagógicas e coexistência de instituições publicas e privadas de ensino;

IV - gratuidade do ensino publico em estabelecimentos oficiais;

$V$ - valorização dos profissionais do ensino, garantindo, na forma da lei planos de carreira para o magistério público, com piso salarial profissional e ingresso exclusivamente por concurso público de provas e títulos, assegurado regime jurídico único para todas as instituições mantidas pela União;

VI - gestão democrática do ensino publico, na forma da lei; 
VII - garantia de padrão de qualidade."

Dentre os princípios retromencionados dois parecem permear todo o trabalho e sustentar a necessidade de uma delimitação legislativa do campo de atuação do professor, o primeiro apontando para a valorização do profissional (art. 206, V) e o segundo demonstrando a intencionalidade do legislador na busca da garantia de uma educação de qualidade (art. 206, VII).

Assim, podemos dizer que a educação profissional, em nível nacional, com base nos princípios constitucionais, regula-se principalmente:

a) pela Lei Federal $n^{\circ}$ 9.394, de 20 de dezembro de 1996, que estabelece as diretrizes e bases da educação nacional (LDB);

b) por orientações emanadas do Conselho Nacional de Educação.

Desde já, firmamos o entendimento que há uma séria preocupação no Brasil com o ensino (como ocorre em qualquer país civilizado); porém, criou-se uma ambiência favorável para o trato da educação através de normativos que ainda se revelam insuficientes, eis que deixam a descoberto o profissional que está no centro do processo, sendo importante que o nosso trabalho toque no ponto crucial da questão: um processo de busca de qualidade na educação exige a profissionalização do professor e a instrumentalização efetiva através de um Estatuto próprio que regulamente a Profissão. Mais adiante, voltaremos a comentar a LDB, comparando-a com outro instrumento de regulamentação jurídica, o Código de Ética, no intuito de apontar para possiveis caminhos a serem percorridos na profissionalização do professor.

\section{A LEGISLAÇÃO INFRACONSTITUCIONAL E SUA INTERPRETAÇÃO}

A Lei de Diretrizes e Bases da Educação ao longo do seu texto traz a expressão "profissionais da educaçãoi" (arts. 14, 61, 64, 67). Notadamente está a se referir ao docente e às atividades de suporte pedagógico, embora trate da educação de forma ampla, compreendendo "os processos formativos que se desenvolvem na vida familiar, na convivência humana, no trabalho, nas instituições de ensino e pesquisa, 
nos movimentos sociais e organizações da sociedade civil e nas manifestações culturais" (art. 1ํㅜ).

A constatação que fazemos é fruto de disposição expressa, pois a LDB traz em seu texto que a finalidade da novel legislação é a de disciplinar a educação escolar, nunca esquecendo que esta deverá vincular-se ao mundo do trabalho e à prática social (art. $1^{\circ}, \S \S 1^{\circ}$ e $\left.2^{\circ}\right)$.

Ainda, relacionado ao contexto normativo em que se encontram os profissionais da educação no Brasil, é importante destacar que a Lei de Diretrizes e Bases da Educação leva em consideração a qualificação para o exercício da docência, nos seguintes termos:

"Art. 65. A formação docente, exceto para a educação superior, incluirá prática de ensino de, no mínimo, trezentas horas.

Art. 66. A preparação para o exercício do magistério superior far-se-á em nível de pósgraduação, prioritariamente em programas de mestrado e doutorado.

Parágrafo único. O notório saber, reconhecido por universidade com curso de doutorado em área afim, poderá suprir a exigência de título acadêmico.

Art. 67. Os sistemas de ensino promoverão a valorização dos profissionais da educação, assegurando-Ihes, inclusive nos termos dos estatutos e dos planos de carreira do magistério público:

I - ingresso exclusivamente por concurso público de provas e títulos;

II - aperfeiçoamento profissional continuado, inclusive com licenciamento periódico remunerado para esse fim;

III - piso salarial profissional;

IV - progressão funcional baseada na titulação ou habilitação, e na avaliação do desempenho;

$V$ - período reservado a estudos, planejamento e avaliação, incluído na carga de trabalho;

VI - condições adequadas de trabalho.

Parágrafo único. A experiência docente é pré-requisito para o exercício profissional de quaisquer outras funções de magistério, nos termos das normas de cada sistema de ensino. (Grifamos).

Por certo, a educação é dever do Estado assegurado constitucionalmente e, nesse sentido, visando a concretizar princípios norteadores do sistema educacional, a Lei de Diretrizes e Bases dispõe sobre a necessidade de qualificação e de experiência para 
o exercício da profissão (embora haja alguns problemas nesse sentido, como discutiremos mais adiante). Ato contínuo, temos que a resolução n 03/97 no seu artigo $3^{\circ}$, parágrafo $1^{\circ}$, ao regulamentar 0 artigo da LDB, estabeleceu que a experiência docente deverá ser de dois anos. Como se vê, a legislação consagra a concepção de que o profissional da educação deve ser primeiramente professor e de que as demais funções do magistério sejam exercidas em etapas posteriores de sua carreira, iniciada sempre pela docência.

Sendo assim, verifica-se que a docência é o eixo central das funções do magistério, tornando-se evidente que o profissional da educação deverá ser, antes de tudo, um professor, a fim de conhecer e experimentar essa relação e ter a exata compreensão do objetivo e da dinâmica da escolarização em todas as suas dimensões.

Entendemos - à unanimidade (ou quase) - que a educação tornou-se premissa da inserção social e da construção da cidadania, sendo portanto tema que deve integrar as discussões políticas da atualidade. E, estando a conquista da cidadania em primeiro plano, são essenciais as reflexões sobre a efetiva profissionalização dos operadores do ensino no Brasil, inserindo-se na conjuntura dos demais debates da atualidade.

Diante disso, percebemos que tanto as normas existentes (texto) quanto a realidade social (contexto) estão a exigir um tratamento mais rigoroso para o exercício da docência. Os profissionais desta categoria carecem de uma regulamentação efetiva que lhes proporcione, entre outras conquistas, as condições necessárias para um trabalho de qualidade, socialmente valorizado e com digna retribuição pecuniária.

\section{CAMINHOS E IMPASSES DA PROFISSIONALIZAÇÃO: UMA ANALOGIA COM PROFISSÕES REGULAMENTADAS}

\subsection{COMPARAÇÃO COM O ASSISTENTE SOCIAL}

A Lei 8.662, de 7 de junho de 1993, dispôs sobre a profissão de Assistente Social, regulando o exercício da profissão e estabelecendo: criação de conselhos (regionais e federais) com personalidade jurídica, habilitação prévia e registro para o exercício da profissão junto aos conselhos, o âmbito de competência do profissional, as atribuições privativas, construção de um código de ética profissional e atribuição de 
competências para julgamento e, de modo geral, os direitos e deveres a que estão submetidos os Assistentes Sociais.

Se uma analogia é possível (e entendemos que sim), haveremos de inferir que a relação social se efetiva a partir de processos cognitivos iniciais possuindo na sua origem o Professor, sendo que o Assistente Social intervém num mundo em que o processo educacional permeia e é parte dos problemas e das soluções. Assim como - Professor, a postura do Assistente Social é investigativa do grupo humano considerado (família, escola, prisões, hospitais) e, num segundo momento, necessita intervir utilizando uma metodologia e/ou teoria. Nada mais lógico, quando defendemos que o profissional da educação deve ser profissionalizado, deduzir que a melhoria do processo e o êxito em termos de qualificação passa por uma efetiva fiscalização que se constrói a partir da norma (texto). O que o Assistente Social já possui, o reconhecimento legal e instrumentos para a sua ação efetiva e eficaz na sociedade, ainda, lamentavelmente, não contempla o professor.

\subsection{COMPARAÇÃO COM O PSICÓLOGO}

Uma outra profissão que permite a comparação é a do psicólogo. Sabemos que a Lei no 4.119, de 27/08/1962, dispôs sobre os cursos de formação em Psicologia e regulamentou a profissão de Psicólogo. Após, a Lei n 5.766, de 20/12/1971, criou o Conselho Federal e os Conselhos Regionais de Psicologia como entes dotados de personalidade jurídica de direito público, com autonomias administrativa e financeira, constituindo, em seu conjunto, uma autarquia, destinados a orientar, disciplinar e fiscalizar o exercício da profissão de Psicólogo e zelar pela fiel observância dos princípios de ética e disciplina da classe. E, por fim, a Resolução do Conselho Federal de Psicologia nº 002/1987 instituiu o Código de Ética Profissional do Psicólogo.

Esta série de regulamentações, em frações de tempo distintas, permitem o exercício e a fiscalização da profissão, implicam o reconhecimento social do profissional, gerando um processo dialético entre texto e contexto que se concluem reciprocamente. O exercício da profissão de Professor necessita da legitimação formal para que, numa interação com o social, o Estado e o indivíduo sejam beneficiados. Assim, propomos a aproximação do Psicólogo e do Professor na sua prática cotidiana, onde observamos que ambos analisam o caso, elaboram um diagnóstico prévio, 
escolhem estratégias e metodologias, o que exige qualificação profissional e desenvolvimento de habilidades e competências específicas para o exercício profissional.

Se compararmos os dispositivos jurídicos que regulamentam o exercício da profissão de professor (Lei Federal $n^{\circ}$ 9.394, de 20 de dezembro de 1996, a LDB), e o exercício da profissão de psicólogo (Lei № 4.119, de 27/08/1962, Decreto № 53.464, de 21/01/1964, que dispõem sobre a profissão de Psicólogo; Resolução do Conselho Federal de Psicologia № 002/1987, que cria o Código de Ética Profissional), verificaremos que, embora se aplique bem a ambas as profissões algumas viscerais considerações dentre as constantes da Exposição de Motivos do Código de Ética do Psicólogo, que abaixo destacamos, sem pretender exaustividade,

... o comportamento humano, [está] sujeito, ele próprio, à complexidade de contínuas e profundas transformações.

... . [entender que] o homem é um ser de relação, sujeito a contínuas mudanças na sua luta por ocupar, a cada momento, o espaço que lhe compete no mundo.

... [pressupor] essa transitoriedade que é própria do homem à procura de seu destino e significação.

...colocar-se, de um lado, numa reflexão constante do ser humano como sujeito de mudanças e, de outro lado, cristalizar com normas propostas de comportamento [referentes ao profissional], ações que por sua natureza são dinâmicas.

...[referindo-se ao profissional] expressar, de um lado, a dinamicidade própria da liberdade, do risco e da criação e, de outro lado, mostrar um conjunto de ações ou comportamentos que seja representativo da realidade e da relatividade do dia-a-dia, com os quais o homem se põe diariamente em contato.

...preocupação [ética do profissional] com o amanhã do indivíduo, grupos e sociedade...

enquanto que o Decreto № 53.464, de 21/01/1964 (que regulamenta a Lei no 4.119, de 27 de agosto de 1962, que dispõe sobre a profissão de Psicólogo) confere proteção ao psicólogo contra o exercício ilegal da profissão (ao mesmo tempo em que cria a própria possibilidade da ilegalidade desse exercício profissional situando-a na forma de contravenção já prevista em lei),

Título I

Do exercício profissional 
Art. $1^{\circ}$ É livre em todo o território nacional o exercício da profissão de Psicólogo, observadas as exigências na legislação em vigor e no presente Decreto.

Parágrafo Único - A designação profissional de Psicólogo é privativa dos habilitados na forma da legislação vigente. (grifamos)

a LDB, no Artigo 62ำ que trata especificamente da formação dos profissionais da Educação, não contém nenhuma salvaguarda semelhante, abrindo, assim, espaço para amadorismos.

Art. 62ํ: A formação de docentes para atuar na educação básica far-se-á em nível superior, em curso de licenciatura, de graduação plena, em universidades e institutos superiores de educação, admitida, como formação mínima para o exercício do magistério na educação infantil e nas quatro primeiras séries do ensino fundamental, a oferecida em nível médio, na modalidade Normal. (grifamos)

Em acréscimo, se atentarmos à expressão em destaque, o mesmo artigo convida de certa forma a um conceito aligeirado da competência para o exercício da profissão de professor.

Já no Decreto № 53.464, posto em comparação, uma concessão análoga para o psicólogo está absolutamente descartada. O padrão de qualidade na formação deste último se mantém de forma escrupulosa em lei, independentemente das condições de trabalho ou do público-alvo desta categoria profissional. Assim, somente se admitem três possibilidades, segundo o Artigo 6: Bacharel em Psicologia, Licenciado em Psicologia e Psicólogo, com uma importante ressalva (novamente grifada):

Art. $16^{\circ}$ Ao aluno que concluir o curso de Bacharelado será conferido o diploma de Bacharel em Psicologia.

Art. $17^{\circ}$ Ao aluno que concluir o curso de Licenciado será conferido o diploma de Licenciado em Psicologia.

Art. 18ํ Ao aluno que concluir o curso de Psicólogo será conferido o diploma de Psicólogo.

O leitor poderá remeter este artigo ao Parágrafo Único do Artigo 1ํㅡ, retranscrito abaixo:

Parágrafo Único - A designação profissional de Psicólogo é privativa dos habilitados na forma da legislação vigente. 
Outro obstáculo a remover rumo à profissionalização do professor é a exogenia dos discursos constituidores e das ações promotoras da valorização profissional, a qual contrasta flagrantemente com o caráter endógeno de seus correspondentes no território do psicólogo. Em outras palavras, cabe a outros que não o professor a defesa de seus interesses (muitos talvez estejam experimentando pela primeira vez uma sensação de estranhamento diante desta constatação). Se não, vejamos. Eis o que diz a LDB (grifo nosso):

Art. 67. Os sistemas de ensino promoverão a valorização dos profissionais da educação, assegurando-lhes, inclusive nos termos dos estatutos e dos planos de carreira do magistério público:

I - ingresso exclusivamente por concurso público de provas e títulos;

II - aperfeiçoamento profissional continuado, inclusive com licenciamento periódico remunerado para esse fim;

III - piso salarial profissional;

IV - progressão funcional baseada na titulação ou habilitação, e na avaliação do desempenho;

$V$ - período reservado a estudos, planejamento e avaliação, incluído na carga de trabalho;

VI - condições adequadas de trabalho.

Longa experiência tem-nos mostrado que, ao menos na área da docência, não tem proporcionado bons frutos delegar a terceiros o zelo pela categoria e por sua boa imagem em sociedade.

Se, agora, compararmos a LDB com o Código de Ética Profissional do Psicólogo, diferenças flagrantes saltam à vista (grifos nossos):

Das responsabilidades gerais do Psicólogo

Art. $1^{\circ}$ São deveres fundamentais do Psicólogo:

(...)

prestar serviços psicológicos em condições de trabalho eficientes, de acordo com os princípios e técnicas reconhecidos pela ciência, pela prática e pela ética profissional; 
zelar para que o exercício profissional seja efetuado com a máxima dignidade, recusando e denunciando situações em que o indivíduo esteja correndo risco ou 0 exercício profissional esteja sendo vilipendiado;

participar de movimentos de interesse da categoria que visem à promoção da profissão, bem como daqueles que permitam o bem-estar do cidadão.

Art. 2ํo Asicólogo é vedado:

(...)

acumpliciar-se com pessoas que exerçam ilegalmente a profissão de Psicólogo ou qualquer outra atividade profissional;

Das responsabilidades e relações com Instituições Empregadoras e Outras

Art. 4 O Psicólogo, para ingressar ou permanecer em uma organização, considerará a filosofia e os padrões nela vigentes e interromperá o contrato de trabalho sempre que normas e costumes da instituição contrariarem sua consciência profissional, bem como os princípios e regras deste Código.

(...)

$\S 2^{\circ}$ - O Psicólogo não estabelecerá com seus colegas, nem aceitará para si, salários que não sejam fixados com dignidade, a fim de que representem justa retribuição pelos serviços prestados.

Das relações com outros profissionais ou Psicólogos

Art. $7^{\circ}$ O Psicólogo terá para com os seus colegas respeito, consideração e solidariedade, que fortaleçam o bom conceito da categoria.

Das relações com a categoria

Art. 15ㅇ P Psicólogo prestigiará as associações profissionais e científicas que tenham por finalidade:

defender a dignidade e os direitos profissionais;

difundir e aprimorar a Psicologia, como ciência e como profissão;

harmonizar e unir sua categoria profissional;

defender os direitos trabalhistas.

Das comunicações científicas e da divulgação ao público

Art. 35ํ O Psicólogo não divulgará, ensinará, cederá, dará, emprestará ou venderá a leigos instrumentos e técnicas psicológicas que permitam ou facilitem o exercício ilegal da profissão.

De tudo que nos pode chamar a atenção nesses excertos do Código de Ética do Psicólogo, queremos destacar neste breve artigo os seguintes pontos, sumariamente e sem pretensão de exaustividade: 
a) Cabe somente ao psicólogo exercer vigilância sobre a qualidade da prestação de serviços e as condições de trabalho de sua categoria.

b) Não só o exercício da profissão é explicitamente reservado à categoria, desencorajados quaisquer amadorismos (seja qual for o pretexto) sob a rubrica de "exercício ilegal da profissão", mas também seus membros são instigados a considerar confidenciais seus conhecimentos práticos, quer aprendidos na graduação, quer desenvolvidos em investigações in-service. Ergue-se, desta forma, uma demarcação territorial, intransponível e assimétrica, entre o profissional e sua alteridade - o leigo.

c) O espírito corporativo, seja no cotidiano profissional, seja nos momentos de mobilização política, é condição sine qua non para a manutenção da boa imagem da categoria.

d) O empenho em preservar esta última não exime o psicólogo de recusar-se a trabalhar em más condições ou com remuneração que se lhe afigure iníqua.

\subsection{O TRISTE HEROÍSMO DE UM "SEM-TERRITÓRIO"}

A ausência de escrúpulos semelhantes no exercício da docência tem sido, a nosso ver, talvez o principal fator na sedimentação de uma imagem vilipendiada, banalizada e mesmo infantilizada do professor em nosso meio, além do notório esvaziamento de seu poder de mobilização e reivindicação.

Podemos fazer um esboço comparativo da situação (e imagem) profissional do professor como categoria, também sem exaustividade:

a) Trata-se de um "sem-território": não Ihe é consignado um conjunto de atribuições específicas na sociedade (daí a idéia nefasta do profissional "polivalente", do "salvador da pátria" - uma espécie de caricatura do "factotum della citá", um triste Fígaro a tirar o leite das pedras na escola).

b) Mesmo a perspectiva de o professor definir para si próprio uma partição integrada de funções (especializações e trabalho em equipe) fica longe de se concretizar, na medida em que não há quaisquer indicações a esse respeito nos artigos da LDB que dispõem sobre a formação docente. A este respeito e a título de comparação, cabe 
ressaltar que o Código de Ética do Psicólogo, em seu Artigo 11ํ, prevê, optativamente, tanto o trabalho em equipe (multifuncionalidade colaborativa) quanto a eleição de metodologias compatíveis com este último.

c) Dado que lhe falta um conjunto de preceitos de ética corporativa, o professor carece de uma tradição de solidariedade e respeito mútuos, tendo que trabalhar e resolver seus problemas geralmente de forma isolada - o que ao longo do tempo não só o defasa do progresso científico e técnico da área, como também o exaure física e psiquicamente, predispondo-o a uma doença profissional crônica denominada burnout, que não raro o deixa semi-incapacitado.

d) A falta de preservação de um conjunto exclusivo de saberes procedimentais cuidado este que delimitaria um território de competências separando o profissional do leigo - contribui para perpetuar tanto a incursão de amadores (eufemisticamente, "amigos (?!) da escola") quanto uma dependência técnica dos "especialistas" da Academia, que prescrevem de seus gabinetes para que o professor execute com docilidade. É o óbvio ululante que esta situação banaliza de maneira atroz a docência.

e) O professor, uma vez que não ocupa o espaço do discurso legitimador endogenamente, depende de terceiros para sua valorização. $E$ isto se torna um problema particularmente sério, na medida em que contribui para perpetuar mitos que distorcem o papel do professor na construção da cidadania. Exemplos típicos são as tele-reportagens que exibem uma professora a ponto de literalmente pagar para trabalhar, tentando atender crianças em contextos sem condições objetivas para trabalho psicomotor e esforço intelectual profícuos. Diante desse quadro, o entrevistador proclama solenemente que "isso é um exemplo de boa professora" (?!). Caberia aqui perguntar - após compararmos a referida situação com as condições de exercício de outras profissões relacionadas ao desenvolvimento humano: Em que sentido?

\section{CONSIDERAÇÕES PROVISORIAMENTE FINAIS}

Tornou-se quase um lugar comum afirmar que vivemos na era da informação e que um dos principais desafios a enfrentar é a inclusão social, sem a qual é impossível sequer falar em construção da cidadania. A educação deve ser encarada como o 
alicerce para a construção da cidadania nesse quadro, merecendo atingir sua maioridade por meio de sua emancipação jurídica.

Para a categoria dos operadores do ensino, isso implica tornar realidade o sonho da efetiva profissionalização, principalmente tendo em vista que tanto as normas existentes (a forma da lei assim como se encontra hoje) quanto a realidade social (as condições objetivas de exercício e o sistema de crenças e mitos que assola a opinião pública) estão a exigir um tratamento mais rigoroso para o exercício da docência. Especialmente pelo enorme alcance social da atividade, sobressai a necessidade premente de uma regulamentação efetiva da profissão, sustentada em princípios constitucionais que apontam para a valorização do professor e que visam um processo contínuo e progressivo de qualidade na educação.

\section{BIBLIOGRAFIA}

A seguinte legislação foi encontrada na página: www.planalto.gov.br

1. Constituição Federal de 1988

2. Lei Federal $n^{\circ}$ 9.394, de 20 de dezembro de 1996

3. Resolução n 03/97 do Conselho Nacional de Educação

4. Lei 8.662, de 7 de junho de 1993

5. Lei no 4.119 , de $27 / 08 / 1962$

6. Lei no 5.766, de 20/12/1971

Os seguintes documentos foram encontrados na página:

www.crpsp.org.br/a_orien/codigo/fr_codigo_etica_indice_htm

7. Resolução CPF no 002/1987 (Código de Ética Profissional do Psicólogo)

8. Apresentação da Resolução CPF nº 002/1987

9. Exposição de Motivos da Resolução CPF nº 002/1987 
NOTAS

1. Profissionais da Educação ou Magistério - são os profissionais que exercem a docência e as atividades de suporte pedagógico direto à docência; incluem, portanto, os docentes e os profissionais de administração, supervisão, inspeção e orientação educacional.

2. Docentes - são os profissionais da educação no exercício da docência, sendo a palavra professores e a expressão profissionais do ensino, em alguns contextos, utilizadas como sinônimo de docência.

3. A título de sugestão, é possível construir o conceito legal de Professor que abrangeria as atribuições ligadas tanto a Docência quanto ao Suporte Pedagógico 